\title{
Performance of TiAIN PVD Coated Carbide Drill when Drilling Titanium 6246 Alloy
}

\author{
Mahros Darsin ${ }^{1,2, a}$, Tim Pasang ${ }^{1}$ and Zhan Chen ${ }^{1}$ \\ ${ }^{1}$ AUT University, Mechanical Engineering Department, 19 St Paul Street, Auckland, New Zealand \\ ${ }^{2}$ University of Jember, Mechanical Engineering Department, JI Kalimantan 37, Jember, Indonesia
}

\begin{abstract}
This article describes the TiAlN PVD coated carbide drill tool performance after being used for drilling of Ti-6246 Titanium alloy. Every drill bit was used for single drilling and then being observed with SEM from flank and rake view. Taguchi method L18 design of experiment was used to find the optimum parameters. Wear was not found in this research, however, the tool delamination and tool chipping was evidenced, even if drilling only $10 \mathrm{~mm}$ depth. Tool experienced built-up edge in the outer blade, inner blade and at the chisel. This BUE can be seen at both view, i.e. rake and flank sides. BUE is the most dominant deterioration and inevitably in drilling this alloy, regardless the parameters applied. Tool delamination may occur during mechanism of peeling off the BUE. While chipping was related to higher feed rate, that may relate to high MRR. Analysing data using Minitab 17 shows that combination of drilling without cooling, $30 \mathrm{~mm}$ deep, cutting speed of $50 \mathrm{~m} / \mathrm{min}$ and feed rate of $0.15 \mathrm{~mm} / \mathrm{min}$ would result in the best performance of TiAlN tool for drilling Ti6246 as received.
\end{abstract}

\section{Introduction}

One of the common applications of TiAlN is for coating the Tungsten carbide tool. There is two ways of applying TiAlN on the base tool material, by physical vapour deposition (PVD) and chemical vapour deposition (CVD). TiAlN coating has a strong chemical stability, a low thermal conductivity and a high wear resistance at $900^{\circ} \mathrm{C}$. The TiAlN coating increases the surface hardness to approximately $3400-3600 \mathrm{Hv}$ and improves the resistance to abrasive wear [1]. Other researchers [2, 3] proved that the $\mathrm{Al}$ element incorporated in TiAlN coating forms the superficial layer $\mathrm{Al}_{2} \mathrm{O}_{3}$ to improve the wear resistance and to enhance the chemical stability.

In machining hard metals, PVD TiAlN has shown its better performance than TiN and TiCN [4]. TiAlN also possessed perfect tribological properties compares to TiN, AlTiN and CrAlN coating [5]. TiAlN coated tools have been used for machining hard metals such as Inconnel718 [6], AISI 414 steel [7], AISI 4340 hardened steel [8], Titanium Ti6Al4V [9].

In this research TiAlN PVD coated carbide insert drill is proposed for drilling Titanium alloy 6246. Ti-6246 has some advantages such as corrosion resistance, low heat conductivity, high hardness, nonmagnetic and wear resistance. In machining point of view, this alloy among hard-to-machine alloy. There are three main reasons why it so. First, its high hot hardness - retain hardness at high

\footnotetext{
${ }^{\mathrm{a}}$ Corresponding author: mahros.teknik@unej.ac.id
} 
temperature. During machining, heat emerges due to friction between tool and workpiece. The heat generated is not able to soften the alloy. Secondly, it is more severe because this alloy has low heat dissipation. The generated heat was absorbed by the tool $(80 \%)$, chips $(10 \%)$ and work material $(10 \%)$ [10]. That is in contrast with the heat distribution in machining steel the percentage is $10 \%, 10 \%$ and $80 \%$ respectively. The last reason is Ti-6246 has high affinity to other materials. In machining, it tends to form built-up edge - debris attachment on the tool.

There are some reasons in the selecting of TiAIN PVD coated carbide for drilling Ti-6246 alloy. TiAlN PVD coated carbide was recommended for higher cutting speed in turning Ti-64 [11]. Ti-64 has some similarities with Ti-6246. In drilling Titanium alloy Ti-64, TiAlN coating tool was more superior to the uncoated tool, it increased tool life by $2416 \%$ at the same cutting speed of $25 \mathrm{~m} / \mathrm{min}$ [12]. In contrast, tool delamination occurred in 5 seconds when face milling of Ti-6246 used TiN coated carbide [13].

To extend of our knowledge, there is no published paper on the performance of TiAlN PVD coated Tungsten carbide for drilling Ti-6246. Studying TiAlN coated drill performance will help to improve machinability of the Ti-6246 alloy.

In this research tool performance was measured by examining the tool condition (or deterioration) after one drilling with certain depth. By definition, tool deterioration is all changes in a cutting part of a tool caused by cutting process [14]. From this definition, all changes of tool may include chipping, wear or addition to the original shape (such as attachment or built-up edge) or crack. Furthermore, ISO define tool wear is a change in shape of the cutting part of the tool from its original shape, resulting from progressive loss of tool material during cutting. Whereas, chipping or brittle fracture is an occurrence of cracks in the cutting part of a tool followed by loss of small fragments of tool material, resulting from crack initiation during cutting. Wear of tool is the condition to measure tool life and tool life itself is one and has been accepted as the most method for machinability judgement criterion [10].

\section{Experimental Procedures}

The tools used were IC908 Sumocham $10 \mathrm{~mm}$ insert type of TAIN PVD coated carbide with included angle $140^{\circ}$. The drill is designed with thinning type - the inner cutting lips has been ground to reduce the chisel side length - the dull part of the tool (Fig 1a). The drill bit then is inserted into the drill body as depicted in Figure 1b. Some blocks of Ti-6246 were prepared with a size of $25 \mathrm{~mm}$ x $25 \mathrm{~mm}$ and vary in height, from $15 \mathrm{~mm}$ to $50 \mathrm{~mm}$. prior to drilling a block was clamped in a fixture which is mounted on a Kistler dynamometer to measure the forces worked during drilling. The dynamometer is connected to a $\mathrm{PC}$ outside the $\mathrm{CNC}$ machine to monitor the process.

Taguchi L18 with 2 level of single factor and other 4 factors with 3 levels were used for designing the experiments as shown in Table 1.

Table 1. Variation of machining parameters and their level.

\begin{tabular}{|c|c|c|c|}
\hline \multirow{2}{*}{$\begin{array}{c}\text { Machining } \\
\text { Parameters }\end{array}$} & \multicolumn{3}{|c|}{ Levels } \\
\cline { 2 - 4 } & Low & Medium & High \\
\hline Coolant & off & - & on \\
\hline $\begin{array}{c}\text { Heat Treatment } \\
* \text { ) }\end{array}$ & AR & HT1 & HT2 \\
\hline $\begin{array}{c}\text { Depth of drilling } \\
\text { (mm) }\end{array}$ & 10 & 30 & 45 \\
\hline $\begin{array}{c}\text { Cutting speed } \\
\text { (m/min) }\end{array}$ & 27 & 35 & 50 \\
\hline $\begin{array}{c}\text { Feed rate } \\
(\mathrm{mm} / \mathrm{min})\end{array}$ & 0.08 & 0.11 & 0.15 \\
\hline
\end{tabular}


*) Three conditions of material: (1) AR: as received, (2) HT1: Heat treated at $870^{\circ} \mathrm{C}$ for three hours then followed air cooled (AC) and (3) HT3: Heat treated at $870^{\circ} \mathrm{C}$ for three hours then followed water quenching (WQ).

Prior to and after drilling, the state of the drill heads were observed using Scanning Electron Microscopy (SEM). To get the constant position observations, a fixture was designed and manufactured from an aluminium block. Two main views of observations of drill heads are shown in Figure 1, i.e. flank view (Fig 1c-i) and rake view (Fig 1c-ii).
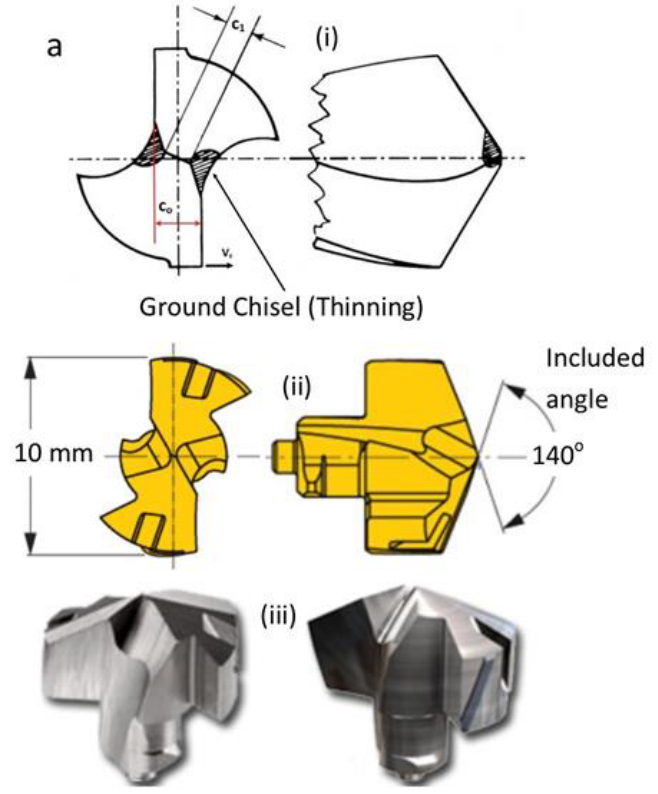
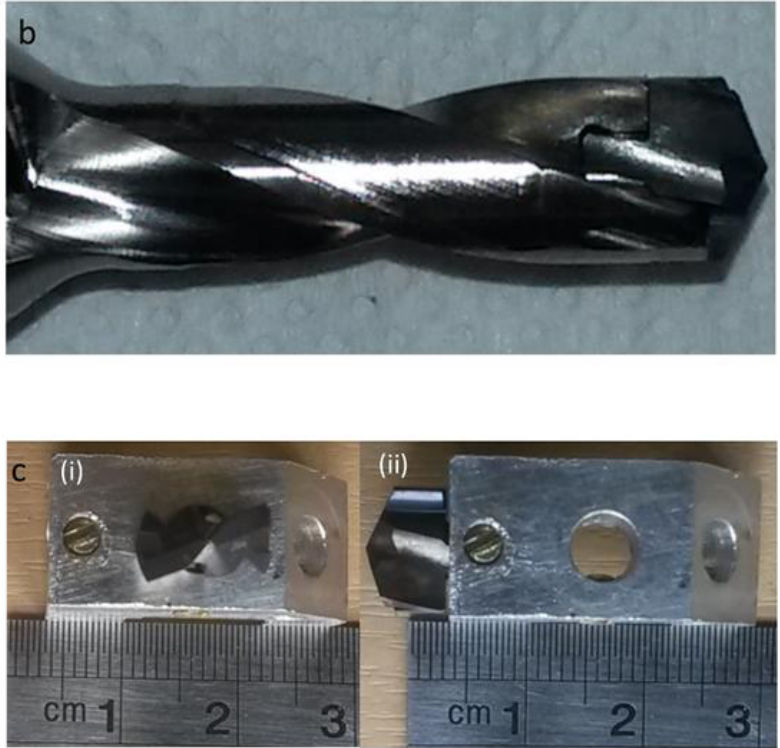

Figure 1. Drill bit type and its main dimension (a), a drill bit mounted on drill body (b), the position of the drill bit when being observed using Scanning Electron Microscopy (SEM): flank view (c-i), rake view (c-ii).

\section{Results and Discussions}

\subsection{Type of Tool Deterioration}

Wear was not observed in all drilling condition. It may due to short time or cycles of drilling. Three types of deterioration were observed in this research. Two types were reducing the tool from its original shape: delamination and chipping; and another is an addition to the original tool shape: builtup edge (Figure 2). Built-up edge is an attachment of debris or segments of chips on the tool. According to Tomac [15], there is three category of a built-up edge. It depends on where they stick on. Built-up edge (BUE) stick on the edge of the tool, built-up layer (BUL) on the lip of rake-layer, flank built-up (FBU) on the lip of flank side [15]. However, in this research, we would refer them all as a built-up edge (BUE). Attachment in the form of built-up edge predominated in all condition of drilling. It happened in all parameters used. Usually, BUE still exists in the vicinity of the chisel to the inner blade and less pronounces in the edge of the outer blade. However, the leftover mark on the tool clearly shown that BUE has been delaminated in this site.

Delamination was the second common type deterioration in this research. When the tool has been delaminated the grain of tool base (WC-Co) is obvious as shown in Figure $2 b_{3}$. Delamination is the loss of coating adhesion to a surface or between coating layers. 
The last but not the least is chipping. Even though chipping rarely happened, we consider it as the most severe tool deterioration. Chipping is a loss of a small fragment of the tool by sudden action. Consequently, pronounced base tool material can be seen clearly.
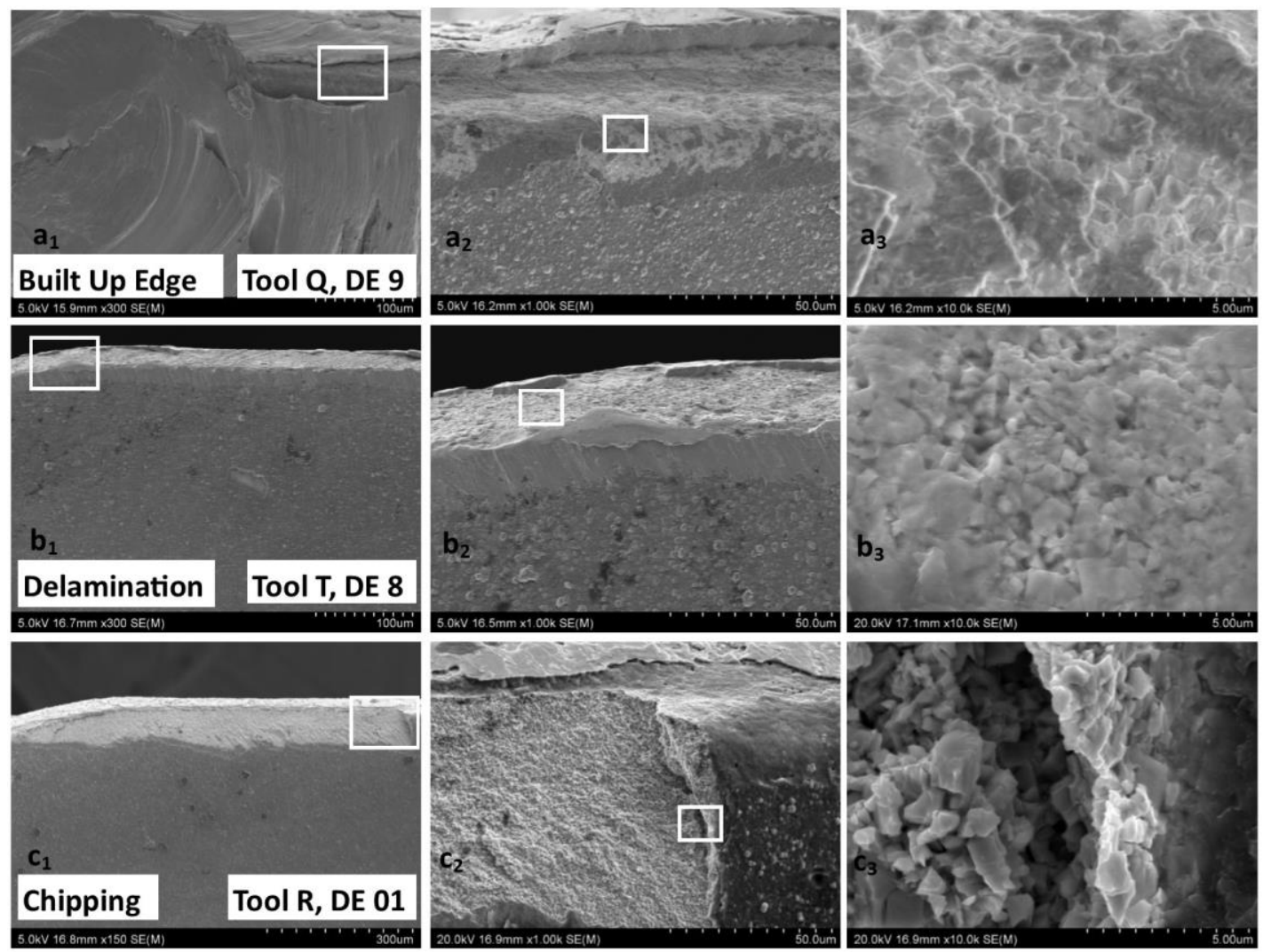

Figure 2. Typical of tool deterioration in drilling Ti-6246.

\subsection{Mechanism of Tool Deterioration}

Built-up edge is the method of adhering particles present during machining to rake face of cutting tool. During drilling there is some amount of microchips or powdered particles will be produced. According to the first law of thermodynamics that total energy of an isolated system is constant. The energy emerged from the cutting process will be converted into the heat, therefore the rake face is experiencing high temperature. When the microchips or powdered particles are moving the rake face of the tool, they will get exposed to the high-temperature environment and some of the particles may get adhered or welded to the rake face of the tool called as a built-up edge.

Built-up edge formation is very common in machining Titanium alloy due to the affinity of this alloy to most of the tool material [16-17]. Built-up edge does not occur in other material, such as steel, when high-speed machining is applied [18]. Therefore, built-up edge formation in machining Titanium alloys is due to its affinity and low cutting speed applied. Thus, a built-up edge still exists in machining titanium alloy because it is nearly impossible to apply high cutting speed in its machining. In the case of drilling, the formation of BUE is inevitable, even if high speed is applied, because the cutting speed varies from the maximum at the peripheral of the outer blade to zero at the chisel. A thick BUE at the vicinity of the chisel and inner blade is shown in Fig. $2 \mathrm{a}_{1}$. Higher magnification (in Fig $2 \mathrm{a}_{2}$ and further in Fig $2 \mathrm{a}_{3}$ ) indicates that Carbide particles (the bright part) of base tool material have been revealed. 
Delamination of TiAlN coating from the base tool material has also reported by Nouari, M. and Makich, H. (2014) [1]. They concluded that coating delamination was the continuation of adhesion and diffusion modes in machining Ti-64. We reluctance to their opinion that delamination is diffusion mode. Diffusion is a physical process due to different concentration. We could not recognise any different concentration between tool surface and the microchips or powdered particles. We also not in the same opinion to the other researchers [ $16 \& 19]$ that the delamination is a chemical reaction, to the fact there was no change to a substance at the molecular level. The BUE is formed and then after a while when a critical load is reached the BUE breaks away from the cutting edge. The mechanism of forming and peeling off may repeat thousand times per second [20]. During the peeling off mechanism, some part tool can be torn away. In the case of coated tool, the coating may be delaminated, as seen in Fig $2 b_{1}, 2 b_{2}$ and $2 b_{3}$ in order of clarity respectively. Actually, the initial delamination has been shown in Fig $2 \mathrm{a}_{3}$. Therefore, delamination is a continuation of BUE peeling off.

Fracture or chipping at the edge corner of the drill was reported by previous researchers [16 \& 21]. They argued that this chipping process related to BUE peeling off mechanism. According to them, the adherent layer was performed on this site due to high temperature. When the temperature is increased, the adhered layer became weak and could no longer withstand the high compressive stress, then the moving chips pulled out the tool particles along with. In this research, chipping randomly occurs at different places, not only happens at the edge corner of the drill. Fig $2 \mathrm{c}_{1}$ shows chipping at the corner between inner and outer blade, about $600 \mu \mathrm{m}$ long. Figure $2 \mathrm{c}_{2}$ shown the edge of chipping area, and from Fig $2 c_{3}$ grains of carbide of base tool material was obvious. Some of the tool chipping associated with high feed rate $(0.15 \mathrm{~mm} / \mathrm{min})$. Trial on drilling with a feed rate of $0.194 \mathrm{~mm} / \mathrm{min}$ proved that severe chipping was obvious at the corner between inner and outer blade. It may relate to high metal removal rate (MRR), a volume of the material that has to be removed in a certain time. When a higher volume of material has to be removed in a shorter time, a higher force needed. Therefore, the tool chipping may be caused by a combination of high force and BUE peeling off mechanism.

\subsection{Performance of the TiAIN Tool}

In regards with the mechanism of tool deterioration, the rank from light to heavy deterioration is BUE, delamination and then chipping. Therefore, we will quantify the degree of deterioration as 1 to 3 . The note 1 is for only BUE was observed, note 2 when BUE and delamination have happened, and notation 3 if there was a tool chipping. Observations were carried out at four main section, viz. at the chisel, at the inner blade, at the corner of the inner and outer blade and at the outer blade. Then, total tool deterioration is the cumulative value of four areas of observation. An example of calculation of tool deterioration of design experiment (DE) 1 is presented in Figure 3. On DE1 there are BUE, delamination, chipping and chipping at the four areas of observations. Therefore, the tool deterioration of DE1 is $1+2+3+3=9$ (Fig 3a). The result of all experiments is presented in Table 2 .

At the Chisel

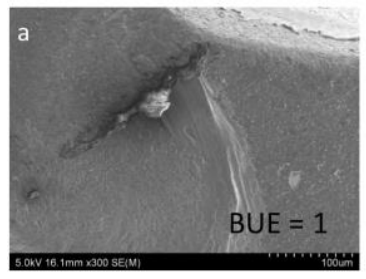

DE 1, Tool R

Total deterioration

$=1+2+3+3=9$
At the Inner Blade

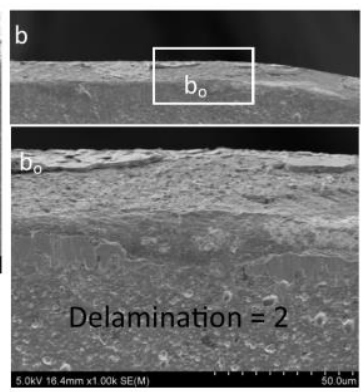

At the Corner of Inner and Outer Blade

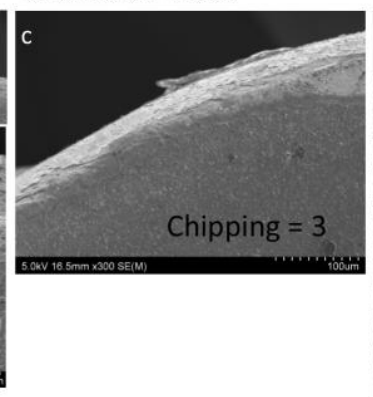

At the Outer Blade

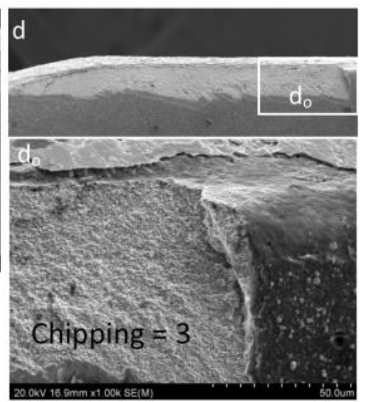

Figure 3. An example of calculating the value of tool deterioration. 
Table 2. Tool deterioration as machining parameters changing.

\begin{tabular}{|c|c|c|c|c|c|c|}
\hline Experiment & Coolant & HT & $\begin{array}{c}\mathrm{h} \\
(\mathrm{mm})\end{array}$ & $\begin{array}{c}\text { Vc } \\
(\mathrm{m} / \mathrm{min})\end{array}$ & $\begin{array}{c}\mathrm{Fr} \\
(\mathrm{mm} / \mathrm{rev})\end{array}$ & $\begin{array}{c}\text { Tool } \\
\text { Deterioration }\end{array}$ \\
\hline 1 & No & $\mathrm{AR}$ & 10 & 27 & 0.08 & 9 \\
\hline 2 & No & $\mathrm{AR}$ & 30 & 35 & 0.11 & 6 \\
\hline 3 & No & $\mathrm{AR}$ & 45 & 50 & 0.15 & 6 \\
\hline 4 & No & HT1 & 10 & 27 & 0.11 & 8 \\
\hline 5 & No & HT1 & 30 & 35 & 0.15 & 5 \\
\hline 6 & No & HT1 & 45 & 50 & 0.08 & 10 \\
\hline 7 & No & HT2 & 10 & 35 & 0.08 & 7 \\
\hline 8 & No & HT2 & 30 & 50 & 0.11 & 5 \\
\hline 9 & No & HT2 & 45 & 27 & 0.15 & 8 \\
\hline 10 & Yes & $\mathrm{AR}$ & 10 & 50 & 0.15 & 4 \\
\hline 11 & Yes & $\mathrm{AR}$ & 30 & 27 & 0.08 & 7 \\
\hline 12 & Yes & $\mathrm{AR}$ & 45 & 35 & 0.11 & 8 \\
\hline 13 & Yes & HT1 & 10 & 35 & 0.15 & 5 \\
\hline 14 & Yes & HT1 & 30 & 50 & 0.08 & 7 \\
\hline 15 & Yes & HT1 & 45 & 27 & 0.11 & 7 \\
\hline 16 & Yes & HT2 & 10 & 50 & 0.11 & 7 \\
\hline 17 & Yes & HT2 & 30 & 27 & 0.15 & 10 \\
\hline 18 & Yes & HT2 & 45 & 35 & 0.08 & 8 \\
\hline
\end{tabular}

The tool performance is the opposite meaning of the tool deterioration, therefore we were using "Smaller is Better" quality characteristic criteria of main effect plot of means to find minimum effect of tool deterioration of each machining parameters as presented in Figure 4. We can see that variation coolant application gave the least effect on tool performance. To keep the block as received (AR) will give the least effect to deterioration. In our previous publication [22] it was stated that AR most likely to be as forged condition. The HT2 has increased the hardness of the block to $335 \mathrm{HV}$, in compare to $288 \mathrm{HV}$ in AR condition. HT1 did not change the hardness but it has changed the grain to be smoother than AR [22]. Drilling of up to $30 \mathrm{~mm}$ deep result in the lower rate of tool deterioration, while drilling $45 \mathrm{~mm}$ lead to rapid tool deterioration. Cutting speed and feed rate influenced greatly to the tool deterioration. Applying either cutting speed of 35 or $50 \mathrm{~m} / \mathrm{min}$ will not change the tool performance. In term of economics, higher cutting speed is preferable. The higher the feed rate the smaller is the tool deterioration. According to the minimum value of mean value each parameter, it should be an ideal if we apply these following parameters during drilling: with coolant, AR, $30 \mathrm{~mm}$ deep, VC 50 $\mathrm{m} / \mathrm{min}$ and Fr $0.15 \mathrm{~mm} / \mathrm{min}$. 


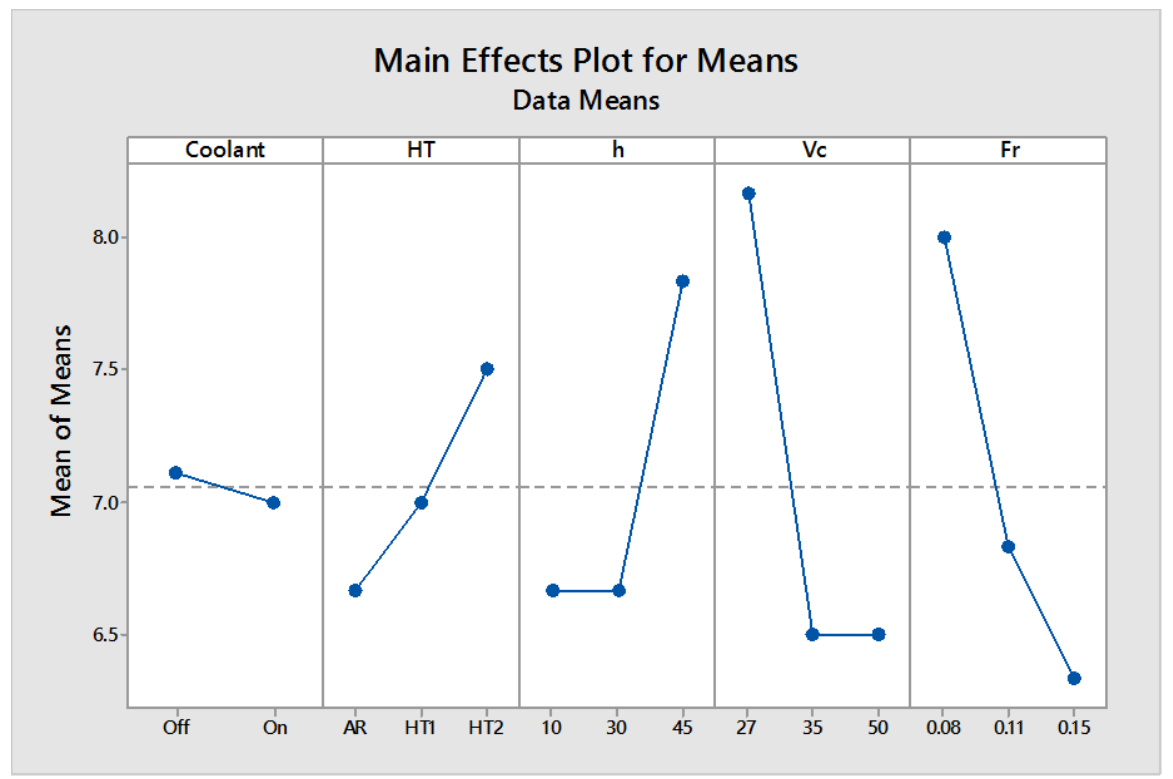

Figure 4. Effect of machining parameters on tool performance.

\section{Conclusions}

Following the above discussion, we may come to some conclusions. First, the built-up edge is unavoided tool deterioration in drilling Ti-6246. The cycle of BUE formation through forming and peeling off mechanism may lead to delamination of TiAlN coating from the carbide substrate tool. Whereas, tool chipping was caused by combination of high force and BUE peeling off mechanism. Last, the best performance of TiAlN PVD coated WC-Co carbide drill will be achieved in drilling Ti6246 block as received (as forged) when using these parameters: with coolant, $30 \mathrm{~mm}$ deep, cutting speed of $50 \mathrm{~m} / \mathrm{min}$ and feed rate of $0.15 \mathrm{~mm} / \mathrm{min}$ simultaneously.

\section{Acknowledgement}

We would like to thank Ministry of Research, Technology and Higher Education of Republic Indonesia through the DIKTI scholarship that financially supports the main author to pursue his $\mathrm{PhD}$ degree at the Auckland University of Technology.

\section{References}

1. M. Nouari and H. Makich. Metals, 4, 335-358 (2014).

2. S.S. Gill, R. Singh, H. Singh, J. Singh, Int. J. Mach. Tools Manuf., 51, 25 - 33 (2011).

3. J. Castanho, M. Vieira, J. Mater. Process. Technol., 143, 253-257 (2003).

4. P.C. Jindal, A.T. Santhanam, U. Schleinkofer, A.F. Shuster, Int. J. of Refractory Metals and Hard Materials, 17, 163-170 (1999).

5. L. Aihua, D. Jianxina, C. Haibinga, C. Yangyanga, Z. Juna, Int. J. of Refractory Metals and Hard Materials, 31, 82-88 (2012).

6. Z. Haoa, D. Gaoa, Y. Fanb, R. Han, Int. J. of Mach. Tools and Manuf., 51, 12, 973-979 (2011).

7. S.K. Khrais, Y.J. Lin, Wear, 262, Issues 1-2, 64-69 (2007).

8. CH.R.V. Kumar, P. K. Nair, B. Ramamoorthy, Int. J. Machining and Machinability of Materials, 3, Nos. 1/2 (2008).

9. N. Andriya, P.V. Rao, and S. Ghosh, Proc. of the WCE III, London, U.K., 2012). 
10. S. Pervaiz, I. Deiab, B. Darras, A. Rashid, M. Nicolescu, Adv. Mat. Research, 685, 68-75 (2013)

11. S. Pervaiz, A. Rashid, I. Deiab, \& M. Nicolescu, Mat. and Manuf. Proc., 29 (3) 219-252 (2014).

12. S. Sharif \& EA. Rahim, J. Mat. Proc. Tech., 185 (1-3), 72-76. (2007).

13. S. Sharif, E.A. Rahim, A.S. Mohruni, \& A. Jawaid, Int. Conf. on Leading Edge Manufacturing in 21st Century. Nagoya (2005).

14. ISO 8688-2, International Organisation for Standardization, Genève (1989).

15. N. Tomac, K. Tonnessen, F.O. Rasch, \& T. Mikac, Advanced Manufacturing Systems and Technology, CISM Courses and Lectures No 486, Springer Wien, New York (2005).

16. J.L. Cantero, M.M. Tardío, M. M., J.a. Canteli, M. Marcos, M., \& M.H. Miguélez, Int. J. of Mach. Tools and Manuf., 45 (11), 1246-1255 (2005).

17. E.A. Rahim, S. Sharif, Z. Ahmad, A.S. Mohruni, \& I.A. Syed, Int. Conf. on Leading Edge Manufacturing in 21st Century (pp. 3-7). Nagoya, (2005).

18. J. Kümmel, J. Gibmeier, E. Müller, R. Schneider, V. Schulze, \& A. Wanner, Wear, 311 (1-2), 2130 (2014).

19. M. Nouari, A. Ginting, Surface \& Coating Tech. 200, 5663 - 5676, (2006).

20. M.A. Dittrich, in answering the question in Research date "How does the built-up edge lead to surface damage" https://www.researchgate.net/post/How_does_the_built-up_edge_lead_to_ surface_damage [October 1, 2016]

21. Z. Rihova, K. Saksl, C. Siemers, \& D. Ostroushko, WASET, 68, 1515-1518 (2012).

22. M. Darsin, T. Pasang, Z. Chen, Twenty-fifth Int. Conf. on Processing and Fabrication of Advanced Materials (University of Auckland, New Zealand, January 2017) 